Reylan B. David, MD

William L. Lim, MD

Department of Otorhinolaryngology

Head and Neck Surgery

Saint Luke's Medical Center
Correspondence: Dr. Reylan B. David Department of Otorhinolaryngology

Head and Neck Surgery

Saint Luke's Medical Center

279 E. Rodriguez Ave., Quezon City 1102

Philippines

Phone: (632) 7275543

Telefax:(632) $7231199(\mathrm{H})$

Email: reylandavid@gmail.com

Reprints will not be available from the author.

The authors declared that this represents original material that is not being considered for publication or has not been published or accepted for publication elsewhere, in full or in part, in print or electronic media; that the manuscript has been read and approved by the authors, that the requirements for authorship have been met by the authors, and that the authors believes that the manuscript represent honest work.

Disclosures: The authors signed a disclosure that there are no financial or other (including personal) relationships, intellectual passion, political or religious beliefs, and institutional affiliations that might lead to conflict of interest.

\section{Congenital Bilateral Vocal Fold Paralysis in a two-year-old Girl}

Vocal fold paralysis is an otolaryngologic disorder that is more prevalent in the adult population. Its occurrence in children has been documented in the literature. We report a case of congenital bilateral vocal fold paralysis and discuss the issues surrounding its ultimate diagnosis and management.

\section{CASE REPORT}

Three months prior to consult, a five-year-old girl started to have noisy (whistling), difficult breathing lasting throughout the day and becoming louder if she cried. She had no cough, colds, fever, or voice changes. Suspecting asthma, an attending pediatrician at a private tertiary hospital emergency room administered salbutamol nebulization affording temporary relief of dyspnea, but the noisy breathing persisted. The girl was discharged on salbutamol syrup to be taken for episodes of difficulty breathing, without any laboratory work-ups.

Two months before consult, another pediatrician prescribed co-amoxiclav and bromhexine for the persistent noisy breathing, without any improvement. Still no work-ups were requested.

A month later, the noisy breathing was louder and associated with difficulty breathing, alar flaring and dynamic chest movements. Suspecting foreign-body aspiration, a tertiary government hospital pediatrician requested chest radiographs that showed minimal infiltrates and no hyperinflation, inconsistent with the working impression. She was referred to our institution for bronchoscopy and possible foreign body extraction.

At our institution, further review of history revealed a Caesarian section for premature rupture of membranes, with cord coil noted on delivery. The perinatal history was otherwise unremarkable.

The girl had been diagnosed with bronchial asthma at two years of age when the noisy breathing was first noted, and had been given Salbutamol syrup as needed for episodes of difficulty breathing. There had been no feeding difficulties and her developmental milestones were at par with age. Immunizations were also complete.

Physical examination revealed respiratory distress with biphasic stridorous breath sounds (heard louder over the neck) with bilateral alar flaring and subcostal and chest wall retractions. Examination of the throat, ears and nose was unremarkable, as was the neurological exam.

A repeat Chest X-ray (Figure 1) showed confluent opacities in both lower lobes and shouldering of the subglottic trachea in the frontal projection. No foreign body was appreciated, and a subglottic stenosis and/or tracheomalacia were considered.

Awake flexible laryngoscopy (Figure 2) revealed bilateral immobile vocal folds fixed in paramedian position. Tracheobronchoscopy under general anesthesia showed no hypopharyngeal or tracheal lesions up to the level of the carina. A tracheotomy was performed and a Shiley size 4.5 tracheostomy tube was inserted.

After much consultation with her relatives, it was decided to follow her closely due to the possibility of spontaneous resolution of bilateral vocal fold paralysis. 
FEATURED GRAND ROUNDS

After two years of regular follow-up, repeat awake flexible laryngocopy revealed no change in vocal fold status. Direct laryngoscopy with cordotomy and arytenoidectomy were then performed. (Figure 3) Two weeks post-operatively, the patient was successfully decannulated.

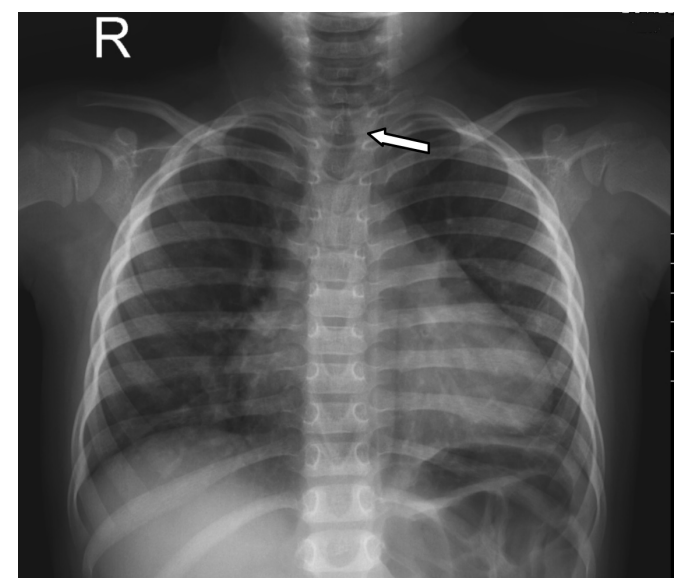

Figure 1. Chest X-ray showing confluent opacities in both lower lobes. Note shouldering at subglottic area (indicated by arrow)
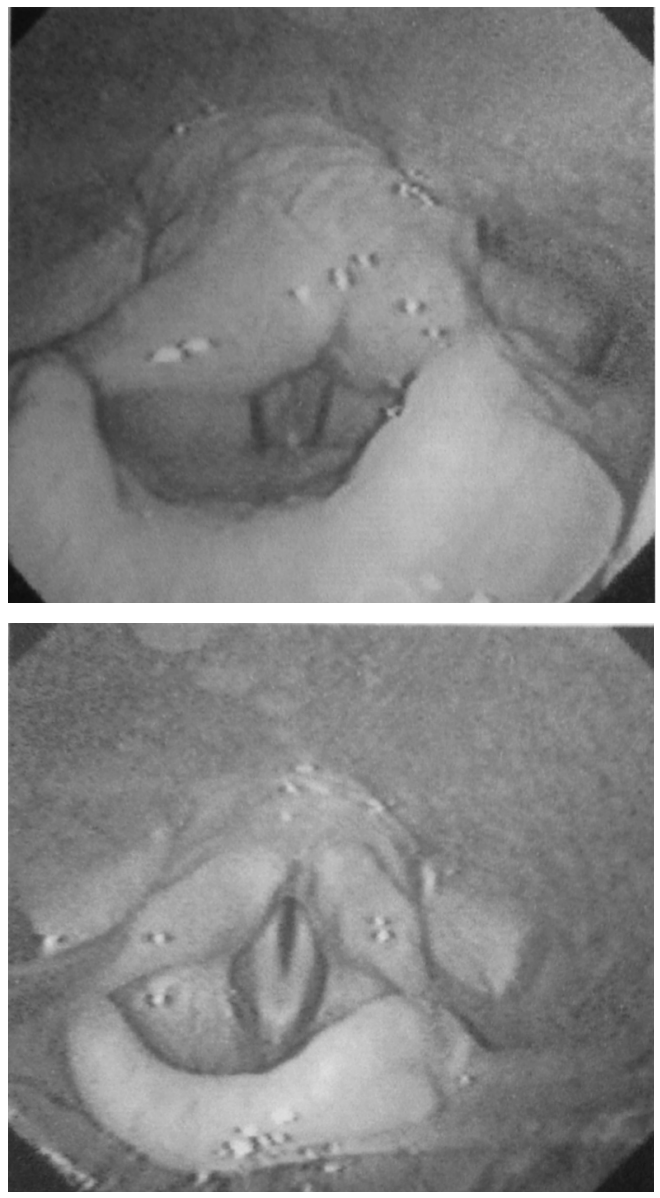

Figure 2. Awake Flexible Laryngoscopy stills showing closed (top) and open (bottom) phase with absent arytenoid movement

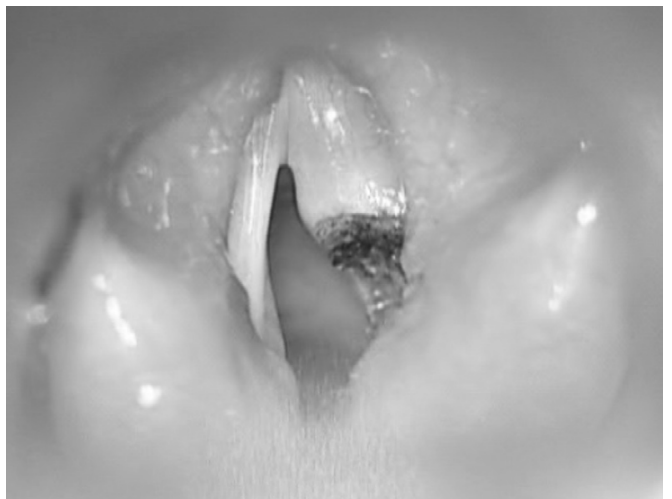

Figure 3. Post-operative view if the larynx of the patient

\section{DISCUSSION}

Stridor represents one of the most common complaints of children presenting with upper airway pathologies. It is defined as an "abnormal sound produced by air passing through an airway lumen of decreased caliber."1

Despite the abundance of literature describing and differentiating this symptom, it would not be uncommon for physicians to mistake this for a wheeze ${ }^{2}$ - an adventitious lung sound. One important point in determining whether a certain breath sound is stridorous or not is the location where the sound is heard loudest: stridorous sounds being heard louder in the neck and wheezing sounds heard best in the lungs. ${ }^{3}$

Stridor may be classified based on timing -- whether it is expiratory, inspiratory or biphasic $c^{4,5}$ Determining the timing of stridor allows one to narrow a multitude of differentials. (Table 1)

Table 1. Types of Stridor and associated Pathology ${ }^{4}$

\begin{tabular}{|l|l|l|}
\hline \multicolumn{1}{|c|}{ Stridor } & \multicolumn{1}{|c|}{$\begin{array}{c}\text { Site of } \\
\text { Obstruction }\end{array}$} & \multicolumn{1}{|c|}{ Pathology } \\
\hline Inspiratory & $\begin{array}{l}\text { Above the vocal } \\
\text { folds }\end{array}$ & Supraglottic Mass, Croup, Epiglotitis \\
\hline Expiratory & $\begin{array}{l}\text { Below the vocal } \\
\text { folds }\end{array}$ & Foreign Body, Tracheomalacia \\
\hline Biphasic & $\begin{array}{l}\text { At and/or below } \\
\text { vocal fold level }\end{array}$ & Foreign body, Bacterial tracheitis \\
\hline
\end{tabular}

*Adapted with permission from Maloney E, Meakin G. Acute stridor in children. Contin Educ Anaesth Crit Care Pain 2007; 7(6):183-186. doi:10.1093/bjaceaccp/ mkm041

However, the co-existence of upper and lower airway pathologies in a patient with stridor may complicate the diagnosis. Hence, further workups may be required.

There are no hard and fast indications of what imaging or modality to request in the assessment of a child with stridor. In this case, a chest $\mathrm{X}$-ray showed equivocal findings. Flexible endoscopy followed, and revealed the disorder. Rigid tracheobronchoscopy ruled out 


\section{FEATURED GRAND ROUNDS}

concomitant tracheal lesions such as laryngomalacia, which is the most common associated anomaly. ${ }^{6}$

Congenital bilateral vocal fold paralysis, defined as reduced or absent mobility of both vocal folds in children is an uncommon disorder. A study by Ahmad et al. estimated the incidence of congenital bilateral vocal fold paralysis to about $0.9 \%$ of all cases of vocal fold paralysis. ${ }^{7}$ The causes of this rare disorder include central nervous system diseases (most common of which is Arnold-Chiari malformation), muscular dystrophies, autoimmune disorders and trauma (arytenoid dislocation). Most cases however are idiopathic. ${ }^{8}$

In our case, trauma (cord coil) seems to be the only positive event that may actually be the precipitating factor. However, even after repeated histories, there is a significant disparity between the presumed cause (cord coil) and the start of symptoms at about 2 years of age. Labeling this case as idiopathic may also be quite premature since an underlying neuromuscular disorder, though rare may present later in life between 4 months to 7 years. ${ }^{9}$ Case reports of bilateral vocal fold paralysis in the local literature are scarce. ${ }^{10-12}$

The most common complaint of this airway pathology is stridor with $32 \%$ presenting after one year of age. ${ }^{8}$ One of the most controversial issues regarding this problem is the value of laryngeal electromyography in diagnosis. While its value in adults with vocal fold immobility is recognized, its role in children is questionable. A study by Berkowitz showed that a normal EMG may be a finding in children with bilateral vocal fold paralysis. ${ }^{13}$

These reasons, aside from the fact that the patient had no other history of neck trauma and that the procedure is technically difficult with the potential for more damaging complications on account of the smaller laryngeal apparatus of the child compared to an adult precluded the application of laryngeal electromyography in this case.

Another controversy is the use of imaging modalities such as CT Scan and MRI. The role of these ancillaries is supposedly to rule out central nervous system and peripheral nerve lesions. But while neurological and thoracic pathologies must be considered in the assessment of vocal fold paralysis, in the face of a normal neurological and chest examination, such exams are unnecessary and may in fact cause untoward and needless stress on the patient.

Our patient had a normal neurological and developmental exam as well as a normal chest and lung exam. In case of idiopathic bilateral vocal fold paralysis, Berkowitz et al..$^{14}$ opined that "blockade of glycinergic inhibitory neurotransmission by strychnine acts pre-synaptically on postinspiratory laryngeal constrictor motorneurons to induce firing during inspiration" as a suggested mechanism and perhaps the reason why EMG findings may be normal in this condition.

But the decision and timing to perform definitive surgery or observe (maintain tracheostomy tube) is perhaps the most significant issue to consider. Factors to consider include impact on language, emotional, and intellectual development, tracheostomy complications, capacity of caregivers to provide home care and possibility of spontaneous recovery. ${ }^{15}$ Each of these factors must be taken into consideration and weighed prior to decision making. Parents must also be informed and included in this process.

The rationale for observation has been emphasized in a study by
Daya et al. ${ }^{8}$ wherein some children showed recovery after age 5 with the longest time of recovery at age 11 years old. In case of non-resolution, a variety of surgical techniques can be done - none showing a clear advantage over the other. ${ }^{16}$

After two years of regular follow-up, observing no significant change in vocal fold status, the parents decided to opt for surgery. Laser arytenoidectomy and cordotomy were chosen because studies have shown it to be superior to other surgical techniques in terms of decannulation rate ${ }^{16}$ and voice preservation and it was a familiar procedure in our institution.

In this procedure, in which an Accupulse Lumenis 40 ST (Yokneam, Israel distributed by Spectromed) carbon dioxide laser machine was used, the posterior one-third of the left vocal fold along with a portion of the left vocal process was ablated. (Figure 3) No major complications were noted during the procedure.

Two weeks postoperatively, the patient was successfully decannulated. Four months after the procedure, the mother reported no further episodes of difficulty of breathing and very minimal speech deficiencies. She also noted increased confidence and cheerfulness.

This case demonstrates how a careful history and physical examination (with minimal diagnostic studies) allows for precise diagnosis without the use of costly interventions such as a CT Scan, MRI or Electromyography and enumerates the factors that must be considered in choosing the best management for the patient.

\section{ACKNOWLEDGEMENTS}

We would like to thank Dr. Joel Romualdez and Dr. Ray Casile for their suggestions and encouragement that have made the writing of this manuscript possible.

\section{REFERENCES}

1. Mitchell RB, Pereira KD. Pediatric otolaryngology for the clinician. In: Brown DJ. Stridor. Humana Press; 2009 p. 137

2. Downing ET, Braman SS, Fox MJ, Corrao WM. Factitious asthma. Physiological approach to diagnosis. JAMA. 1982 Dec 3; 248(21):2878-81.

3. Hollingsworth HM. Wheezing and stridor. Clin Chest Med. 1987 Jun; 8(2):231-40.

4. Maloney E, Meakin G. Acute stridor in children. Contin Educ Anaesth Crit Care Pain 2007; 7(6):183186. doi:10.1093/bjaceaccp/mkm041

5. Cotton RT, Reilly JS. Stridor and airway obstruction. In: Bluestone C, Stool S, Kenna M editors. Pediatric Otolaryngology. $3^{\text {rd }}$ ed. Philadelphia, PA: WB Saunders Co; 1995 p275-86.

6. Tan HKK, Holinger LD. How to evaluate and manage stridor in children. J Respir Dis. 1994; 15(3):245-260.

7. Ahmad S, Muzamil A, Lateef M. A study of incidence and etiopathology of vocal cord paralysis. Indian J Otolaryngol Head Neck Surg. 2002 Oct; 54(4):294-6.

8. Daya H, Hosni A, Bejar-Solar I, Evans JN, Bailey CM. Pediatric vocal fold paralysis: A long-term retrospective study. Arch Otolaryngol Head Neck Surg. 2000 Jan; 126(1):21-25.

9. Lapena JF Jr, Berkowitz RG. Neuromuscular disorders presenting as congenital bilateral vocal fold paralysis. Ann Otol Rhinol Laryngol. 2001 Oct; 110(10):952-5.

10.Saludo RC, Bautista M. Bilateral midline abductor paralysis of the vocal folds. Sto Tomas J Med 1997 [Abstract only] Available from: http://herdin.ph/index.php?option=com_herdin\&controll er=research\&task=view\&cid[0]=21029

11. Alonzo D, De Leon A. Etiology of bilateral vocal fold paralysis: A pin in a haystack. Philipp Otolaryngol Head Neck Surg. 1991:86-88.

12.Vinco V, Pio F, Feliciano R. Tracheotomy versus watchful waiting for neonatal bilateral midline vocal fold paralysis: A case report. Far Eastern University - Dr. Nicanor Reyes Medical Foundation Medical Journal 2006; 12(1):15-19.

13. Berkowitz RG. Laryngeal electromyography findings in idiopathic congenital bilateral vocal cord paralysis. Ann Otol Rhinol Laryngol. 1996 Mar; 105(3):207-12.

14.Berkowitz RG, Sun QJ, Pilowsky PM. Congenital bilateral vocal fold paralysis and the role of glycine. Ann Otol Rhinol Laryngol. 2005 Jun; 114(6):494-8.

15.Graham JM, Scadding GK, Bull PD. Pediatric ENT. In: Shine N, Prescott C, editors. Acquired disorders of the larynx in children. United Kingdom: Springer 2007 p.208

16.Gupta AK, Mann SB, Nagarkar N. Surgical management of bilateral immobile vocal folds and long term follow up. J Laryngol Otol. 1997 May; 111(5):474-7. 